\title{
Three-dimensional poro-elasto-plastic model for wave-induced seabed response around submarine pipeline
}

\author{
X.L. Zhang ${ }^{\mathrm{a}, *}$, C.S. Xu ${ }^{\mathrm{a}, 1}, \mathrm{Y}$. Han ${ }^{\mathrm{b}, 2}$ \\ a The Key Laboratory of Urban Security and Disaster Engineering of Ministry of Education, Beijing University of Technology, Beijing 100124, China \\ ${ }^{\mathrm{b}}$ Institute of Geographic Sciences and Natural Resources Research, Chinese Academy of Sciences, Beijing 100101, China
}

\section{A R T I C L E I N F O}

\section{Article history:}

Received 25 July 2014

Received in revised form

23 October 2014

Accepted 6 November 2014

Available online 26 November 2014

Keywords:

Three-dimensional model

Seabed response

Poro-elasto-plastic

Submarine pipeline

\begin{abstract}
A B S T R A C T
The evaluation of the wave-induced excess pore pressure around a buried pipeline is particularly important for pipeline engineers involved in the design of offshore pipelines. Existing models for the wave-induced seabed response around submarine pipeline have been limited to poro-elastic soil behavior and de-coupled oscillatory and residual mechanisms for the rise in excess pore water pressure. To overcome the shortcoming of the existing models, in this study a three-dimensional poro-elastoplastic soil model with submarine pipeline is established, in which both oscillatory and residual mechanisms can be simulated simultaneously. With the proposed model, a parametric study is conducted to investigate the relative differences of the predictions of the wave-induced pore pressure with poro-elasto-plastic model. Based on numerical examples, it can be concluded that the poro-elastoplastic behaviors of soil have more significant influence on wave-induced pore pressure of seabed around submarine pipeline. As the seabed depth increases, the normalized pore pressures decrease rapidly at the upper part of seabed, and then change slightly at the lower part of the seabed. Soil permeability and wave period have obvious influence on the wave-induced normalized pore pressure.
\end{abstract} (c) 2014 Elsevier Ltd. All rights reserved.

\section{Introduction}

Wave-induced seabed instability is one of the key factors that must be considered in the design of foundation in the vicinity of marine structure such as pipelines and breakwaters. It has been well documented that ocean waves propagating over the ocean surface exert dynamic pressure fluctuations on the sea floor. The dynamic pressure fluctuations further induced excess pore pressure within the soil skeleton, and then subsequently lead to the variation of stresses in seabed. This mechanism involved in this process is rather complicated since it is a coupled problem among soil, pore fluid and structures. Furthermore, it is vital because that it could lead to the reduction of strength or even liquefaction of the foundation around marine structures. It has also been reported that the soil supporting the pipeline may fail due to liquefaction, resulting in the self-burial of the entire pipeline $[1,18]$. Moreover, it has been observed that a deep scour hole exists near the tip of a marine structure [5]. Without proper maintenance at these sites, failure of structures may occur.

\footnotetext{
* Corresponding author. Tel.: +86 15210581913.

E-mail addresses: zhangxiaoling31@163.com (X.L. Zhang), xuchenshun@bjut.edu.cn (C.S. Xu), yhan@igsnrr.ac.cn (Y. Han).

1 Tel.: + 8613401111718 .

2 Tel.: + 8615011550313
}

Generally speaking, two mechanisms of the wave-induced seabed response in the rise in pore water pressure have been observed in the field measurements and laboratory experiments, depending upon the way the excess pore pressure is generated $[15,23]$. One is caused by residual or progressive nature of the excess pore pressure, which appears at the initial stage of cyclic loading. This type of soil response is similar to that induced by earthquakes, which resulted in the build-up of the excess pore pressure. The other is generated by transient or oscillatory excess pore pressure that is accompanied by the damping of amplitude and phase lag in the pore pressure $[22,7,8]$.

Numerous investigations for the wave-induced seabed response have been carried out since the 1970s. Among these, analytical approximations have been developed by various researchers such as Madsen [11], Yamamoto et al. [22], Mei and Foda [14], and Jeng [7,8]. Numerical simulations also have been widely applied to examine such a problem in recent years. Cheng and Liu [4] considered a buried pipeline in a region that is surrounded by two impermeable walls. Magda [13] considered a similar case with a wider range of degree of saturation. Luan et al. [10] considered soil-pipeline contact effects and inertial forces in a new model. At the same time, experimental work has attracted attention from researcher and pipeline engineers. Teh [19] considered the two recent contributions to the problem of the onbottom stability of marine pipelines on liquefied seabed. 
All the aforementioned investigations have been limited to poro-elastic model. It has been well known that poro-elastic models are only valid for small deformation. For large deformation, especially for the case of seabed of seabed instability, the modeling of the soil behavior requires a more sophisticate model such as elasto-plastic models. To further investigate dynamic response of three-dimensional poro-elasto-plastic model for seabed around submarine pipeline under wave loading, a finite element program DYNE3WAC (DYNamic Earthquake Analysis Program 3D Window Version for ACadiemic) [16] is used in this paper. The 3D poro-elasto-plastic model is based on the fully implicit $u-p$ approximation of the Boit formulation [3]. The fully coupled Boit dynamic equations were employed, together with the $u-p$ approach (skeleton displacement $u$ and pore pressure $p$ ), in which the fluid acceleration relative to the solid skeleton is negligible. The model can be used for static, consolidation and dynamic situations under drained and undrained conditions.

The contribution of this study is putting forward a 3D poroelasto-plastic model for the wave-seabed interaction around submarine pipeline. With the proposed model, a parametric study is conducted to examine the effects of wave and soil characteristics on the wave-induced soil response around submarine pipelines.

\section{Boundary value problem}

In this study, a three-dimensional problem is considered. A fully buried pipeline (with a radius $0.5 D$ ) is located in a porous seabed of finite thickness $h$ laid upon an impermeable rigid bottom and surrounding by four impermeable walls (see Fig. 1). The wave crests are assumed to propagate in the $x$-direction on the surface of the seabed, while the $z$-direction is measured positive upward from the surface of the seabed.

\subsection{Boundary condition}

For a porous seabed of finite thickness, as shown in Fig. 1, to evaluate the wave-induced seabed response around a buried pipeline, the following boundary conditions are considered.

Firstly, zero displacements and no vertical flow occur at the impermeable horizontal bottom, i.e.

$u_{s x}=0 u_{s y}=0 u_{s z}=0 \frac{\partial p}{\partial z}=0, z=-h$

Secondly, we assume that the bottom frictional stress is small and negligible. The vertical effective normal stress and shear stress vanish and pore pressure is equal to the wave pressure at the

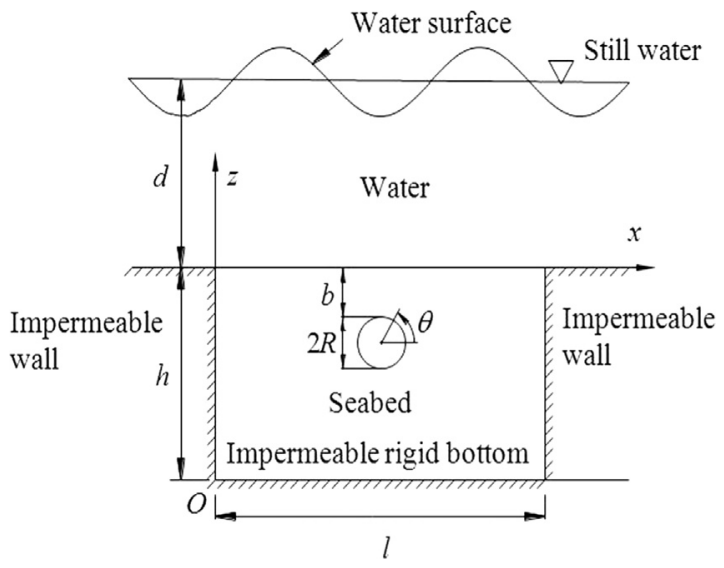

Fig. 1. Definition sketch of a submarine buried pipeline with boundary conditions under wave loading. surface of the seabed, i.e.

$\sigma_{s z}^{\prime}=\tau_{s}=0$

$p=\frac{\gamma_{w} H}{2 \cosh (k d)} \cos (k x-\omega t)$, at $z=0$

where $p_{0}=\gamma_{w} H / 2 \cosh (k d)$ denotes the amplitude of the wave pressure at the surface of the seabed, $d$ is water depth, $H$ is wave height, $k$ is the wave number and $\omega$ is the wave frequency.

Thirdly, we assume that there is no flow through the pipeline wall. This assumption is valid because the pipeline is considered as elastic impermeable material. Thus, the pore pressure gradient on the surface of the pipeline $(r=R)$ should vanish, i.e.

$\frac{\partial p}{\partial n}=0, \quad r=\sqrt{\left(x-x_{0}\right)^{2}+\left(y-y_{0}\right)^{2}+\left(z-z_{0}\right)^{2}}=R$

where $r$ is the parameter of polar coordinate of the pipeline, $x_{0}$ and $z_{0}$ denote the coordinates of the center of the pipeline and $n$ is the normal direction to the surface of the pipeline.

Fourthly, we consider the lateral boundary is impermeable, i.e.

$u_{s x}=0, \frac{\partial p}{\partial x}=0$, at $x=0$ and $x=l$

$u_{s y}=0, \frac{\partial p}{\partial y}=0$, at $y=0$ and $y=m$

\subsection{Soil-pipeline contact effects}

In the analysis of seabed-pipeline interaction, there may exist shear sliding at the interface between soil column and pipeline under wave loading. Most previous investigations for the soilpipeline interaction did not consider the contact effects between soil and pipeline [4]. To simulate the contact effects along soilpipeline interface, a contact element can be established to link two materials in the finite element analysis. Meanwhile, the effects in normal and tangential directions are considered. In the tangential direction, the contact effects include the relative sliding and frictional shear stress. In numerical calculations, the segment method is used. To simulate the effects of interaction at the interface, we need to select the contactor surface and target surface. An important distinction between a contactor surface and a target surface is that in the converged solution, the material overlap at the contactor nodes is zero; the target nodes can overlap the contactor body. In general, the contactor surface should select the surface of fine mesh. Thus, herein, the outer surface of the pipeline is the contactor surface, and the soil column with pipeline is considered as target surface. According to the Coulomb friction theory, the friction shear stress at the interface of seabed and pipeline $\left(\tau_{c}\right)$ can be expressed in terms of frictional coefficient $(\mu)$ and contact pressure at two contact surface $\left(p_{c}\right)$, i.e., $\tau_{c}=\mu p_{c}$ ( $\mu=0.7$ in this study). The shear sliding only occurs when surface drag force is greater than frictional shear stress.

\section{Poro-elasto-plastic model}

\section{1. $u-p$ model}

In general, the three-dimensional poro-elasto-plastic computer program DYNE3WAC [16] is based on the fully implicit $u-p$ approximation of the Biot formulation [3]. The dynamic governing equations for the $u-p$ approximation of the Biot formulation are basically the momentum equations for the soil-fluid "mixture" and the mass balance of the flow. In this section, we only provide a 
brief outline of the theory. Further details can be found in Zienkiewicz et al. [25]

(1) Equilibrium of mixture is written as (in tensorial form)

$$
\sigma_{i j, j}+\rho b_{i}-\rho \ddot{u}_{i}-\underline{\rho_{f}\left(\dot{w}_{i}+w_{j} w_{i, j}\right)}=0,
$$

where $\sigma_{i j}$ is the total stress tensor (tensile positive), $\ddot{u}_{i}$ and $w_{i}$ are the acceleration of the solid skeleton and average (Darcy) fluid velocity respectively, $b_{i}$ is the body acceleration per unit mass, $\rho_{s}, \rho_{f}$ and $\rho$ are the densities of the solid grain, fluid and mixture, respectively, with $\rho=(1-n) \rho_{s}+n \rho_{f}$ and $n$ being the porosity of the porous media. The underlined terms represent the fluid acceleration relative to the solid and the convective terms of the acceleration.

(2) Equilibrium of fluid

$-p_{, i}-F_{i}-\rho_{f} \ddot{u}_{i}-\rho_{f}\left(\dot{w}_{i}+w_{j} w_{i, j}\right) / n+\rho_{f} b_{i}=0$

where $F$ represents the viscous drag forces, assuming the Darcy seepage law can be written as $k_{i j} F_{j}=w_{i}$, where $k$ is the permeability of soil with the dimensions of [length] ${ }^{3}$ [time]/ [mass], which can be expressed by the usual soil mechanics convention $k^{\prime}$, with $k=k^{\prime} / \rho_{f}^{\prime} g^{\prime}$, where $\rho_{f}^{\prime}$ and $g^{\prime}$ are the fluid density and gravitational acceleration, respectively, at which the permeability is measured.

(3) Conservation of mass of fluid phase:

$w_{i, i}+\dot{\varepsilon}_{i i}+\frac{n \dot{p}}{K_{f}}+\frac{(1-n) \dot{p}}{K_{s}}-\frac{K_{T}}{K_{s}}\left(\dot{\varepsilon}_{i i}+\frac{\dot{p}}{K_{s}}\right)+n \frac{\dot{\rho}_{f}}{\rho_{f}}+\dot{s}_{0}=0$

where $w_{i, i}$ is the flow divergence in the unit volume, $\dot{\varepsilon}_{i i}$ is the increased volume due to a change in strain, $n \dot{p} / K_{f}$ is the additional volume stored by compression of void fluid due to the fluid pressure increase, $(1-n) \dot{p} / K_{s}$ is the additional volume stored by the compression of grains by the fluid pressure increase, $-K_{T}\left(\dot{\varepsilon}_{i i}+\dot{p} / K_{s}\right) / K_{s}$ is the change in volume of the solid phase due to a change in the inter-granular effective contact stress, and the underlined part $n \dot{\rho}_{f} / \rho_{f}+\dot{s}_{0}$ corresponds to a change of density and rate of volume expansion of the solid in the case of thermal change and is negligible in general.

The mass conservation equation can be further expressed by using the definition of $\alpha$ and $Q$

$w_{i, i}+\alpha \dot{\varepsilon}_{i i}+\frac{\dot{p}}{Q}+n \frac{\dot{\rho}_{f}}{\rho_{f}}+\dot{S}_{0}=0$

where $K_{T}$ is the average bulk modulus of the solid skeleton, $K_{S}$ is the average material bulk modulus of the solid components of the skeleton and $K_{f}$ is the bulk modulus of the fluid, with $1 / Q \equiv$ $n / K_{f}+(\alpha-n) / K_{s} \cong n / K_{f}+(1-n) / K_{s}$ and $\alpha=1-K_{T} / K_{s}$.

Coupling Eqs. (8) and (10), together with Eq. (7), neglecting the underlined terms which are apparently small under general earthquake analysis, the governing equation can be expressed as follows:

$\sigma_{i j, j}+\rho b_{i}-\rho \ddot{u}_{i}=0$

$\left(k_{i j}\left(-p_{, j}-\rho_{f} \ddot{u}_{j}+\rho_{f} b_{j}\right)\right)_{, i}+\alpha \dot{\varepsilon}_{i i}+\frac{\dot{p}}{Q}=0$

Due to this simplified equation set only containing two dependent variables $u$ and $p$, it is usually called $u-p$ approximation form.

\subsection{Consolidation model}

If we further ignore the acceleration due to the soil motion, the $u-p$ approximation will become the consolidation formulation:

$\sigma_{\mathrm{ij}, j}+\rho b_{i}=0$ $\left(k_{i j}\left(-p_{j}+\rho_{f} b_{j}\right)\right)_{, i}+\alpha \dot{\varepsilon}_{i i}+\frac{\dot{p}}{Q}=0$

Eq. (14) is the conventional consolidation equation [2]. As reported in the previous work [9], the conventional consolidation is sufficient for most cases of the wave-induced soil response in marine environment. Therefore, the consolidation equation is used in this study.

\subsection{Soil constitutive model}

For elastic behavior, based on poro-elastic theory, the stressstrain relationship can be expressed as

$\dot{\sigma}_{i j}=D_{i j k l}^{e} \dot{\varepsilon}_{k l}^{e}$

where $D_{i j k l}^{e}$ stands for elements of constitutive matrix that describes the constitutive stress-strain relation, which can be expressed as the following expression for the case of isotropic elasticity:

$D_{i j k l}^{e}=\lambda \delta_{i j} \delta_{k l}+2 G \delta_{i k} \delta_{j l}$

where $\lambda$ is Lame's constant and $G$ is the shear modulus.

In (15), $\varepsilon^{e}=\varepsilon_{i j}^{e}=\left(u_{i, j}+u_{j, i}\right) / 2$ is the small strain tensor and $u$ is the soil displacement.

The generalized plasticity model by Pastor and Zienkiewicz [17] is used in this study to describe the elasto-plastic soil behavior under wave loadings. This poro-elasto-plastic model used in this paper can simulate the pore water pressure under dynamic loading, including seismic loading and wave loading, which can describe residual mechanism of pore water pressure better. More details about Pastor and Zienkiewicz soil constitutive model can be available from Ou [16] or Zienkiewicz et al. [25].

\subsection{Validations}

First, a 3D linear elastic analysis on wave-induced soil response in finite thickness soil bed was performed and the numerical results were compared with the analytical solution [6]. All degrees of freedom at the two ends of the seabed are totally tied to form a repeated boundary condition appropriately reflecting the infinite lateral extent of the seabed. The design wave condition at North Sea is used as an example [22], i.e., water depth $(d)$ is $10 \mathrm{~m}$ and the wave height $(H)$ is $5 \mathrm{~m}$. For the seabed, the shear modulus and Poisson's ratio are taken to be $10 \mathrm{MPa}$ and $1 / 3$ respectively. The porosity is 0.3 and the permeability is taken as $0.001 \mathrm{~m} / \mathrm{s} .1664$ Lagrangian brick elements of 27-noded are used in the analysis, and the finite element mesh. An excellent agreement between the numerical results (solid symbols and lines) and the analytical solution (hollow symbols and lines) [6] is shown in Fig. 2.

Second, validation of the present model is to compare with a set of experimental data available in the literature [20]. The experimental study was conducted in the J. H. DeFree Hydraulic Laboratory at Cornell University. The input data of seabed characteristics and pipeline characteristics for the experiment and numerical calculations are listed in Tables 1 and 2, and Fig. 3. As Turcotte et al. [20] reported that the sediment was prepared to be uniform. In Fig. 3, the solid line represents the present model, "•" denotes the experimental data, and " $\Delta$ " is the results of Cheng and Liu. As seen in Fig. 3, the present model reasonably agrees with the experimental data, and slightly better than the results of Cheng and Liu. The two numerical results showed slight difference probably because two different numerical methods were applied to this test. Cheng and Liu performed that using a boundary Integral Equation Method, the Finite Element Method is adopted in this paper. 


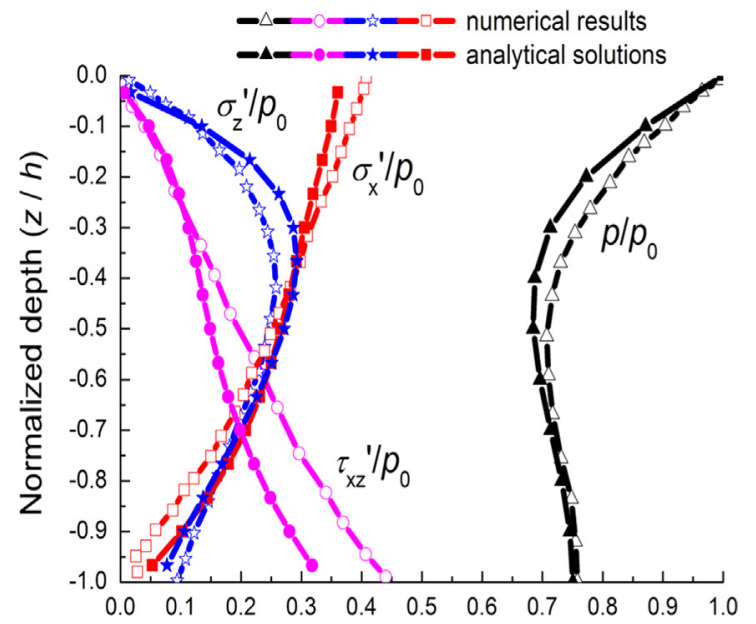

Fig. 2. Comparison between $3 \mathrm{D}$ numerical solution and the analytical solution of Hsu and Jeng.

Table 1

Input data of seabed characteristics for the comparison with the experimental data.

\begin{tabular}{ll}
\hline Seabed characteristics & \\
\hline Seabed length $(l)(\mathrm{m})$ & 4.57 \\
Seabed thickness $(h)(\mathrm{m})$ & 0.826 \\
Modulus of deformation $\left(E_{s}\right)\left(\mathrm{N} / \mathrm{m}^{2}\right)$ & $1.7 \times 10^{6}$ \\
Permeability $\left(k_{s}\right)(\mathrm{m} / \mathrm{s})$ & $1.1 \times 10^{-3}$ \\
Density $\left(\rho_{s}\right)\left(\mathrm{kg} / \mathrm{m}^{3}\right)$ & 1700 \\
Poisson ratio $\left(v_{s}\right)$ & 0.33 \\
Porosity $\left(n_{s}\right)$ & 0.42 \\
Degree of saturation $\left(S_{r}\right)$ & 0.95 \\
\hline
\end{tabular}

Table 2

Input data of pipeline characteristics for the comparison with the experimental data.

\begin{tabular}{ll}
\hline Pipeline characteristics & \\
\hline Buried depth of pipeline $(b)(\mathrm{m})$ & 0.083 \\
Pipeline outer diameter $(D)(\mathrm{m})$ & 0.168 \\
Pipeline thickness $\left(t_{p}\right)(\mathrm{m})$ & 0.01 \\
Young's modulus $\left(E_{p}\right)\left(\mathrm{N} / \mathrm{m}^{2}\right)$ & $3.9 \times 10^{9}$ \\
Density $\left(\rho_{p}\right)\left(\mathrm{kg} / \mathrm{m}^{3}\right)$ & 1400 \\
Poisson ratio $\left(v_{p}\right)$ & 0.35 \\
\hline
\end{tabular}

Another validation of the proposed model for accumulated pore pressure is made with a set of experimental results in the literature [21]. The input data of seabed characteristics and pipeline characteristics for the experiments and numerical calculations are described as follows: the permeability of soil is $7.4 \times 10^{-2} \mathrm{~m} / \mathrm{s}$ and the shear modulus is $6.2 \times 10^{-7} \mathrm{~N} / \mathrm{m}^{2}$; the diameter of pipeline is $40 \mathrm{~mm}$ and the burial depth with $93 \mathrm{~mm}$. The wave characteristic parameters are described as follows: the water depth is $0.4 \mathrm{~m}$, the wave period is $2 \mathrm{~s}$ and wave height is $15 \mathrm{~cm}$ in the experiments. In Fig. 4, the solid line represents the experimental results and the dashed line represents the results of present numerical computation results. Fig. 4(a) shows the results of residual pore pressure with time at the top of buried pipeline and Fig. 4(b) shows the results of residual pore pressure with time at the bottom of buried pipeline. As seen in Fig. 4(a) and (b), the two present numerical results are closed to the experimental data. The results of numerical computation and experiments have the same trend. The numerical results showed slight difference in the latter part of wave loading, it may be because the

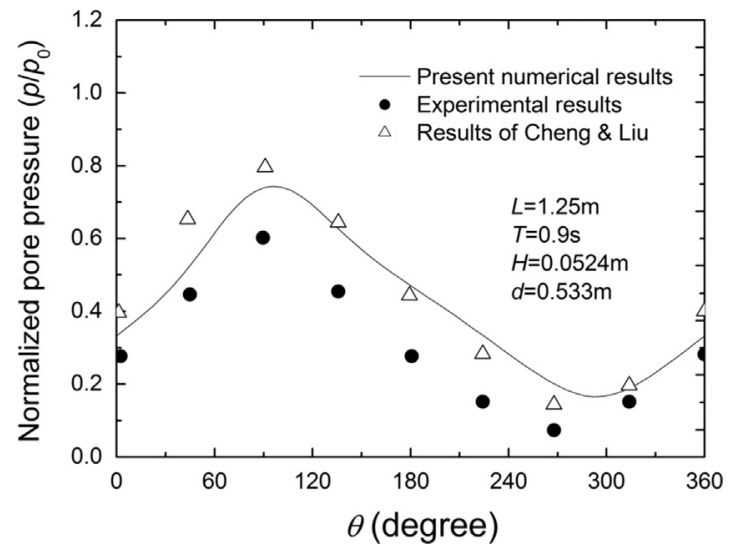

Fig. 3. Comparison with the experimental data and the numerical result of Cheng and Liu.

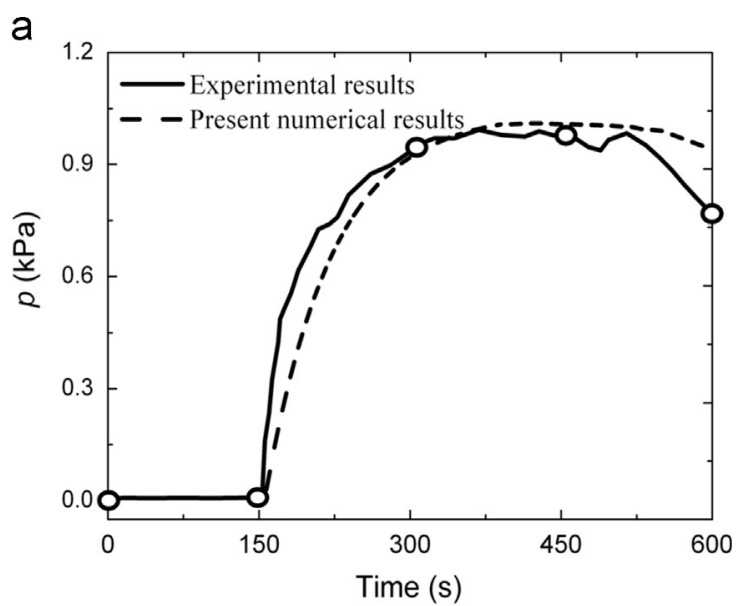

b

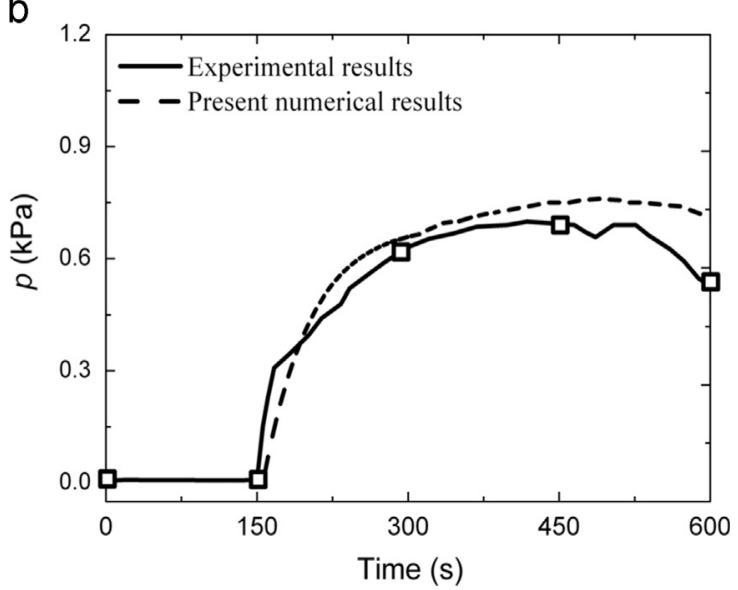

Fig. 4. (a) Comparison of accumulation pore pressure at the top of pipeline with the experimental result of Pan et al. (b) Comparison of accumulation pore pressure at the bottom of pipeline with the experimental result of Pan et al.

accumulated pore pressure dissipates more obviously in the experiments than in the numerical computation.

\section{Results and discussions}

One of contributions of this study is the consideration of elastoplastic soil behavior in the wave-induced seabed response. To illustrate the difference of the predicted wave-induced pore 
Table 3

Input data of seabed characteristics for parametric study.

\begin{tabular}{ll}
\hline \multicolumn{2}{l}{ Seabed characteristics } \\
\hline Seabed length $(l)(\mathrm{m})$ & 75 \\
Seabed thickness $(h)(\mathrm{m})$ & 15 \\
Seabed width $(m)(\mathrm{m})$ & 10 \\
Modulus of deformation $\left(E_{s}\right)\left(\mathrm{N} / \mathrm{m}^{2}\right)$ & $7 \times 10^{7}$ \\
Permeability $\left(k_{s}\right)(\mathrm{m} / \mathrm{s})$ & $1.0 \times 10^{-3}$ \\
Density $\left(\rho_{s}\right)\left(\mathrm{kg} / \mathrm{m}^{3}\right)$ & 1700 \\
Poisson ratio $\left(v_{s}\right)$ & 0.30 \\
Porosity $\left(n_{s}\right)$ & 0.40 \\
Degree of saturation $\left(S_{r}\right)$ & 1.0 \\
\hline
\end{tabular}

Table 4

Input data of pipeline characteristics for parametric study.

\begin{tabular}{ll}
\hline \multicolumn{2}{l}{ Pipeline characteristics } \\
\hline Buried depth of pipeline $(b)(\mathrm{m})$ & 1.0 \\
Pipeline outer diameter $(D)(\mathrm{m})$ & 1.0 \\
Young's modulus $\left(E_{p}\right)\left(\mathrm{N} / \mathrm{m}^{2}\right)$ & $3.0 \times 10^{10}$ \\
Density $\left(\rho_{p}\right)\left(\mathrm{kg} / \mathrm{m}^{3}\right)$ & 2100 \\
Poisson ratio $\left(v_{p}\right)$ & 0.30 \\
\hline
\end{tabular}

Table 5

Input data of wave characteristics for parametric study.

\begin{tabular}{lr}
\hline \multicolumn{2}{c}{ Wave characteristics } \\
\hline Wave length $(L)(\mathrm{m})$ & 23.2 \\
Wave period $(T)(\mathrm{s})$ & 7.5 \\
Wave height $(H)(\mathrm{m})$ & 1.0 \\
Water depth $(d)(\mathrm{m})$ & 1.0 \\
\hline
\end{tabular}

Table 6

Input data of parameters for PZ3 model for parametric study.

\begin{tabular}{lc}
\hline \multicolumn{2}{c}{ Parameters for PZ3 model } \\
\hline$K_{\text {evo }}(\mathrm{kPa})$ & 770 \\
$G_{\text {eso }}(\mathrm{kPa})$ & 1155 \\
$p_{o}^{\prime}(\mathrm{kPa})$ & 4 \\
$M_{g}$ & 1.15 \\
$M_{f}$ & 1.035 \\
$\alpha_{f}$ & 0.45 \\
$\alpha_{g}$ & 0.45 \\
$\beta_{0}$ & 4.2 \\
$\beta_{1}$ & 0.2 \\
$H_{0}$ & 600 \\
$H_{U 0}(\mathrm{kPa})$ & 40,000 \\
$\gamma_{u}$ & 2.0 \\
$\gamma_{D M}$ & 4.0 \\
\hline
\end{tabular}

pressure between the previous elastic and the present elastoplastic models, a parametric study is performed. The influence of wave period, soil permeability and shear modulus and elastoplastic parameters is examined. The input data of seabed characteristic, pipeline characteristic and wave characteristic for numerical examples in parameters study are tabulated in Tables 3-5.

The Pastor Zienkiewicz mark III elasto-plastic Model (PZ3 Model) was adopted in the analysis. The elasto-plastic parameters presented in Table 6 are given by Zienkiewicz et al. [25] to simulate the dense seabed. It should be noted that $K_{\text {evo }}$ in Table 6 represents the value of Bulk modulus of soil at the reference mean effective stress $p_{o}^{\prime}$, and
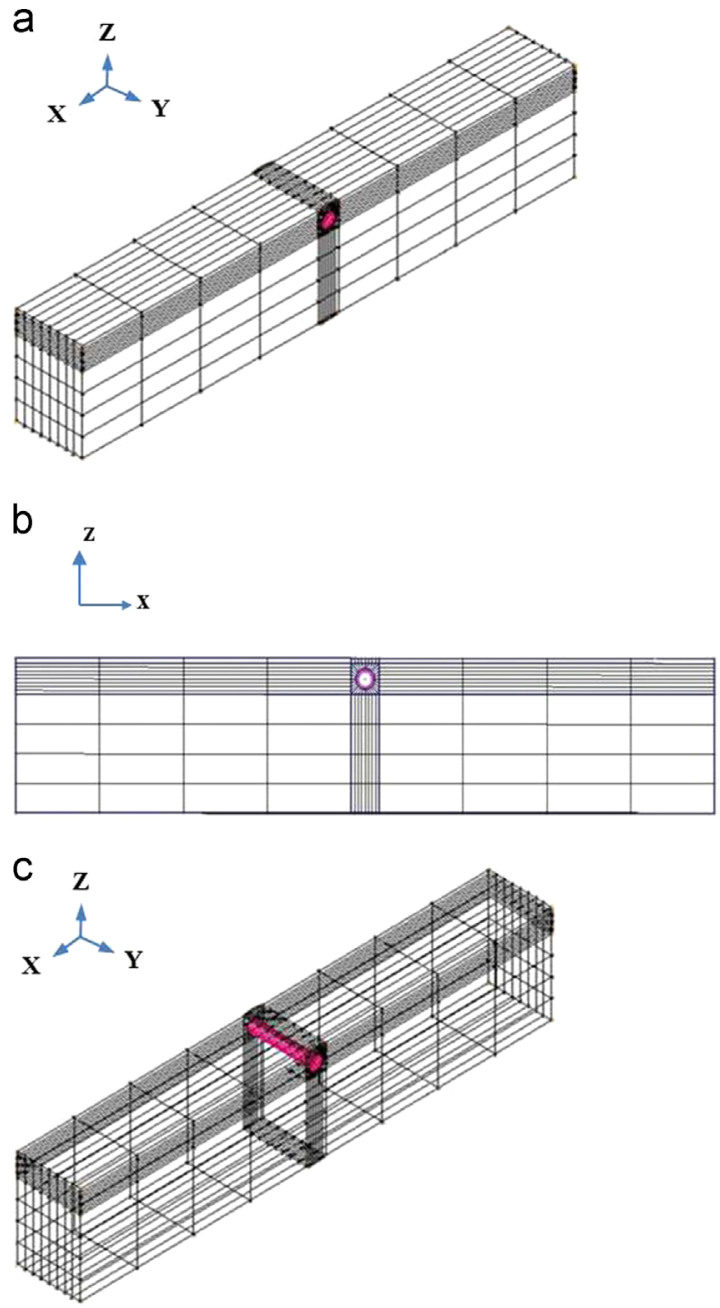

Fig. 5. (a) Three-dimensional mesh of wave-seabed-pipeline interaction problem. (b) The cross-section sketch of Fig. 5(a). (c) Three-dimensional scenography sketch of Fig. 5(a).

$G_{\text {eso }}$ represents the value of three times of shear modulus at the reference mean effective stress ( $G_{\text {eso }}^{\prime}$ represents the shear modulus in the following). The elastic parameters of the linear elastic analysis are calculated based on the value of $K_{\text {evo }}$ and $G_{\text {eso }}$ with the reference mean effective stress at the middle depth of the seabed.

Fig. 5(a) shows the finite element mesh of 3D wave-seabedpipeline interaction problem model. Fig. 5(b) shows the cross-section sketch of Fig. 5(a). Fig. 5(c) shows the three-dimensional scenography sketch of Fig. 5(a). Fig. 5(a), (b) and (c) show all the sketch of the same seabed model with submarine pipeline. As concentration of stresses is expected, local refinement of the finite element mesh always has taken into account in the region near the pipeline. To improve the accuracy of the solution, two different mesh systems are used for the model. As shown in Fig. 6, this kind of mesh has been used for tackling the problem around a pipe-like structure [12].

\subsection{The distributions of pore pressure along seabed depth}

In order to examine the distributions of normalized pore pressure versus soil depth, Fig. 7 shows the results of numerical computation with the proposed 3D pore-elasto-plastic model. In Fig. 7, the normalized pore pressure means the ratio of $p$ to $p_{0}, p$ denotes the excess pore water pressure obtained by numerical computation and $p_{0}$ denotes the amplitude of the wave pressure at the surface of the seabed. The solid line and symbols denote the results of normalized pore pressure of seabed through the pipeline and the dashed line and symbols 


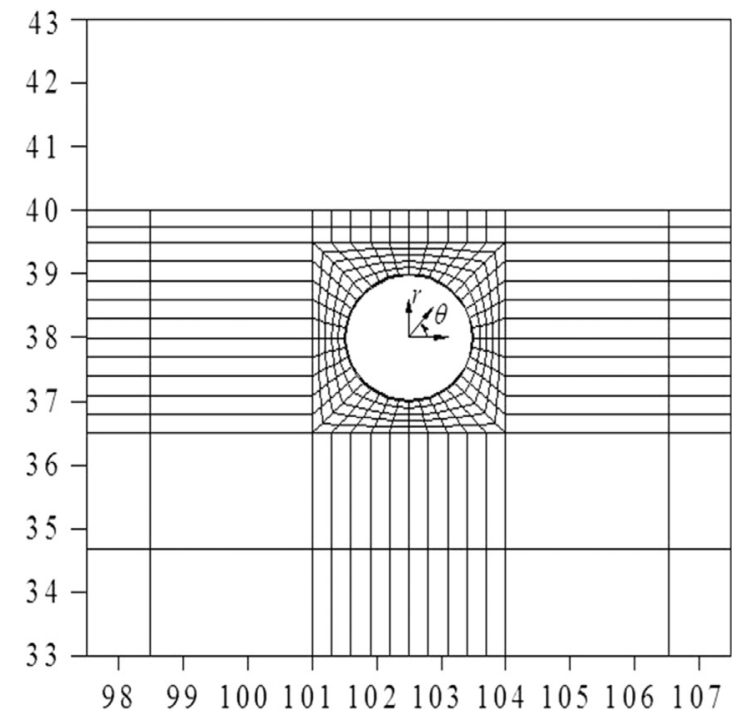

Fig. 6. Finite element mesh in the vicinity of the pipeline.

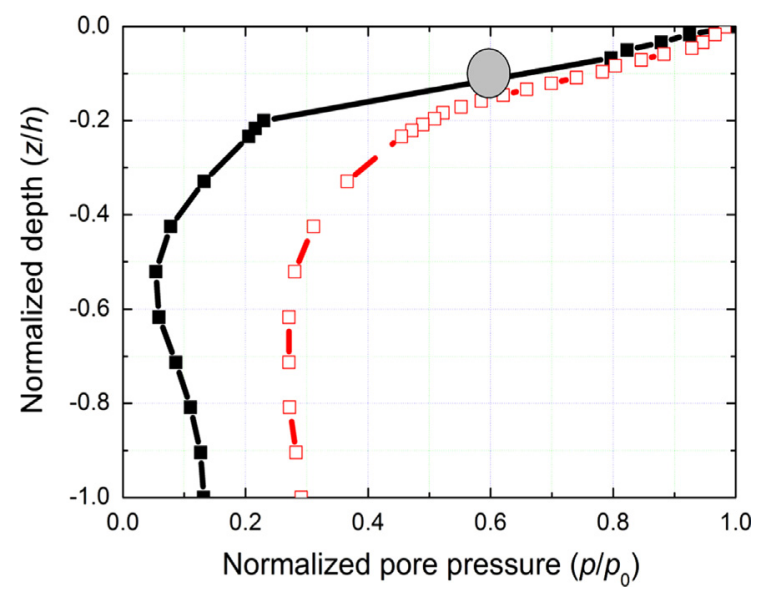

Fig. 7. Vertical distribution of normalized pore pressure $p / p_{0}$ versus $z / h$ at different locations.

denote the results near the pipeline (the distance to the pipeline is $5 \mathrm{~m}$ ). As illustrated in Fig. 7, the result of normalized pore pressure through the pipeline at any fluid node plotted in the figure is smaller than that near the pipeline; it may because of undrained boundary conditions (see Section 2). As seabed depth increases, the normalized pore pressure decreases rapidly at the upper part of seabed, and then changes slightly at the lower part of the seabed. This conclusion agrees with the computation results of 3D pore-elastic model [24].

\subsection{The distribution of pore pressure of seabed around submarine pipeline}

Fig. 8 shows the distribution of normalized pore pressure $p / p_{0}$ of seabed in the vicinity of the buried pipeline with contour plots, values. The solid lines with values denote the results of existing pipeline and the dashed lines denote the ones of free seabed. As seen in Fig. 8, the existence of pipeline has a notable effect on seismic excess pore pressure of seabed around the pipeline. The further the distance from pipeline, the smaller the effect of pipeline. At a given distance away from the pipeline, the effect of existence of pipeline is slight and the distributions of both tend to be consistent.

Fig. 9 illustrates the distribution of normalized pore pressure around submarine pipeline. In Fig. 9, $\theta$ is the polar angle in the

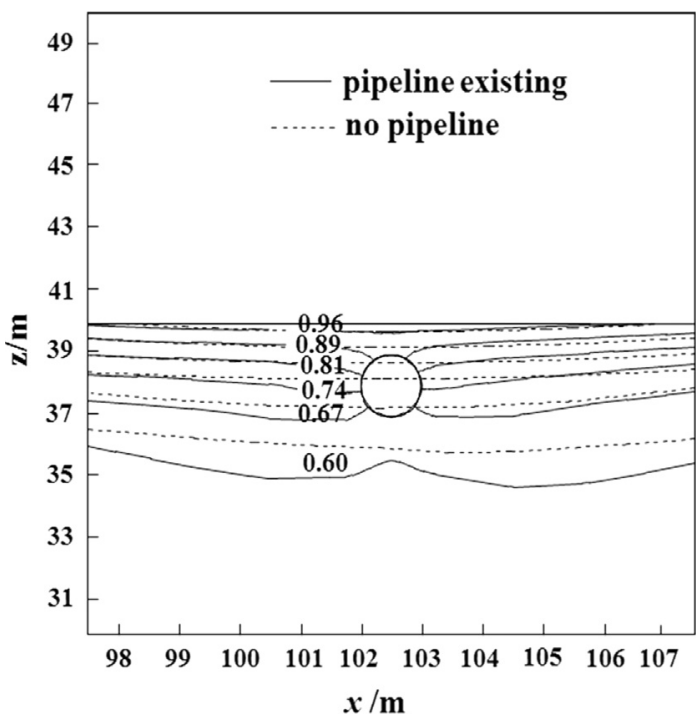

Fig. 8. Distribution of normalized pore pressure $p / p_{0}$ of seabed in the vicinity of the buried pipeline.

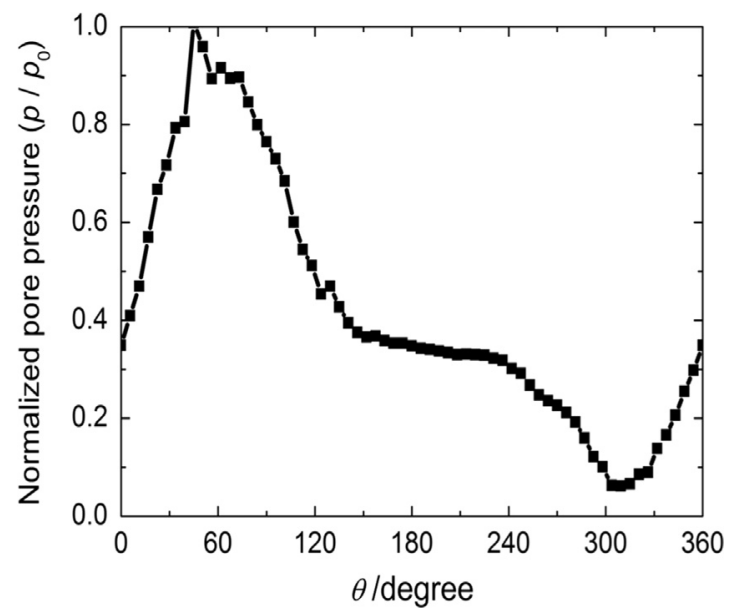

Fig. 9. Vertical distribution of normalized pore pressure $p / p_{0}$ around submarine pipeline.

polar coordinate and it is measured positive in the counterclockwise direction of the pipeline. The value of normalized pore pressure at any fluid node is smaller than 1.0, but the maximum value of normalized pore pressure occurs near $\theta=60^{\circ}$ and the minimum value of that occurs near $\theta=300^{\circ}$. Fig. 9 clearly demonstrates the significant influence of elasto-plastic soil behavior on normalized pore pressure. It is observed that the results of normalized pore pressure are not axisymmetric along the pipeline, which may come from elasto-plastic soil behavior.

\subsection{The comparison of normalized pore pressure with the present elasto-plastic model and elastic model}

The effect of the present elasto-plastic soil model and elastic soil model on normalized pore pressure has been examined; the results are shown in Fig. 10. Fig. 10 clearly demonstrates the obvious differences of elasto-plastic soil behavior and elastic soil behavior on normalized pore pressure. It is noted that the maximum differences of normalized pore pressure between elastic and elasto-plastic soil model can be up to $50 \%$ of $p_{0}$.

Fig. 11 shows the time history curves of excess pore pressure at the bottom and the top point of submarine pipeline with elasto- 


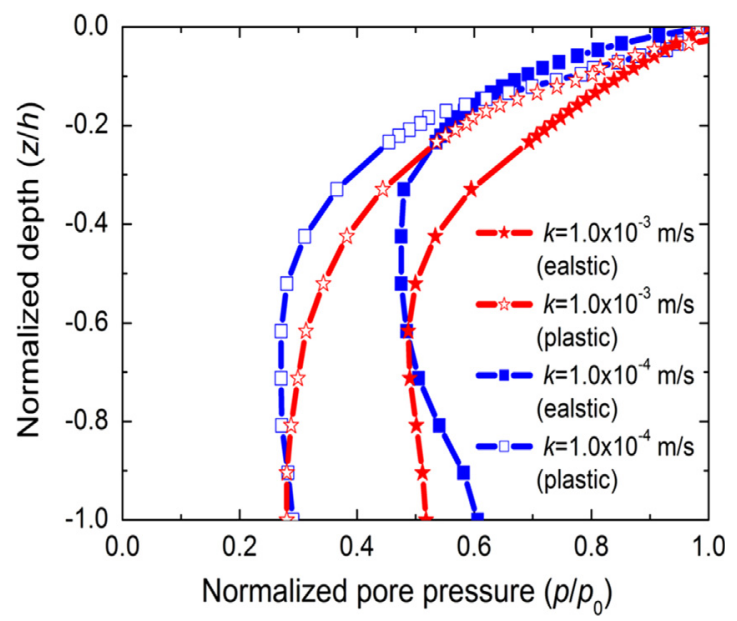

Fig. 10. Vertical distribution of normalized pore pressure $p / p_{0}$ versus $z / h$ with the present elasto-plastic soil model and elastic soil model.

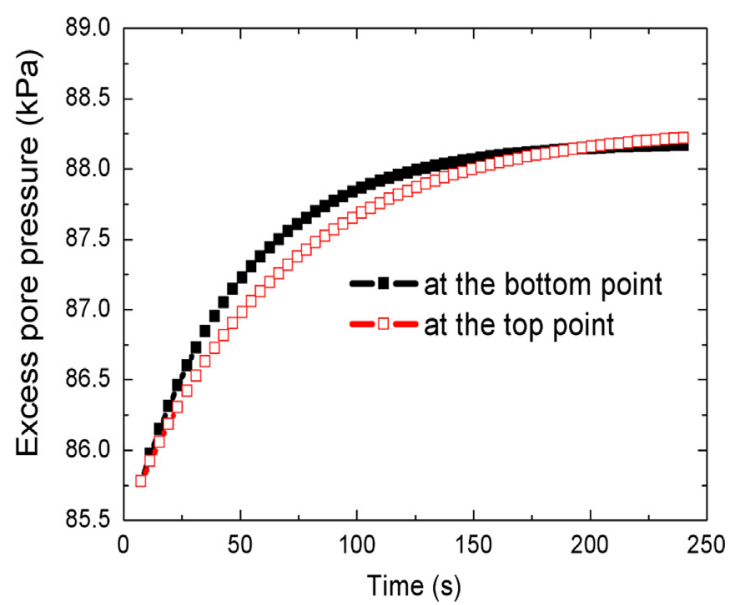

Fig. 11. The time history curves of pore water pressure of seabed with elasto-plastic soil model.

plastic soil model. It shows the significant increase of excess pore pressure in the seabed. It should be noted that no excess pore pressure build-up can be simulated if linear elastic model was adopted in the analysis. It further demonstrates the significant influence of wave-induced pore pressure of seabed around submarine pipeline with elasto-plastic soil model.

\subsection{Effects of soil permeability to the distribution of pore pressure along seabed depth}

Soil permeability is one of the most important soil parameters in this respect, which is a measure of how fast the pore fluid may transfer through the soil matrix. Fig. 12 plots the vertical distributions of normalized pore pressure versus soil depth of various permeabilities $\left(k=1.0 \times 10^{-3} \mathrm{~m} / \mathrm{s}, 1.0 \times 10^{-4} \mathrm{~m} / \mathrm{s}\right.$ and $1.0 \times 10^{-5} \mathrm{~m} /$ s) with elasto-plastic soil behavior. As shown in Fig. 12, the pore pressure with different soil permeability decreases as soil depth increases up to a certain depth, and then changes slightly nearly the lower part of seabed as soil depth increases.

\subsection{Effects of shear modulus to the distribution of pore pressure along seabed depth}

Soil shear modulus is another important soil parameter in the analysis of wave-induced seabed response. According to the mentioned description, the change of shear modulus of soil $G_{\text {eso }}^{\prime}$

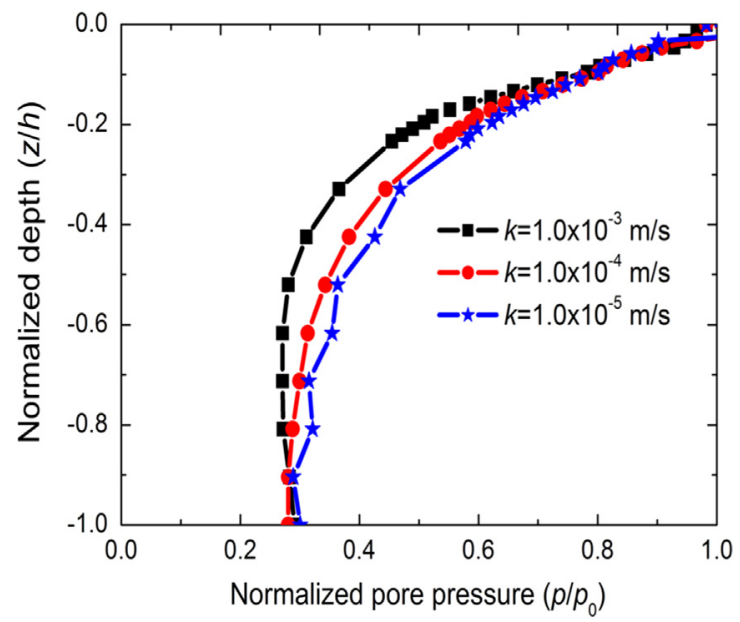

Fig. 12. Vertical distribution of normalized pore pressure $p / p_{0}$ versus $z / h$ with variable soil permeability.

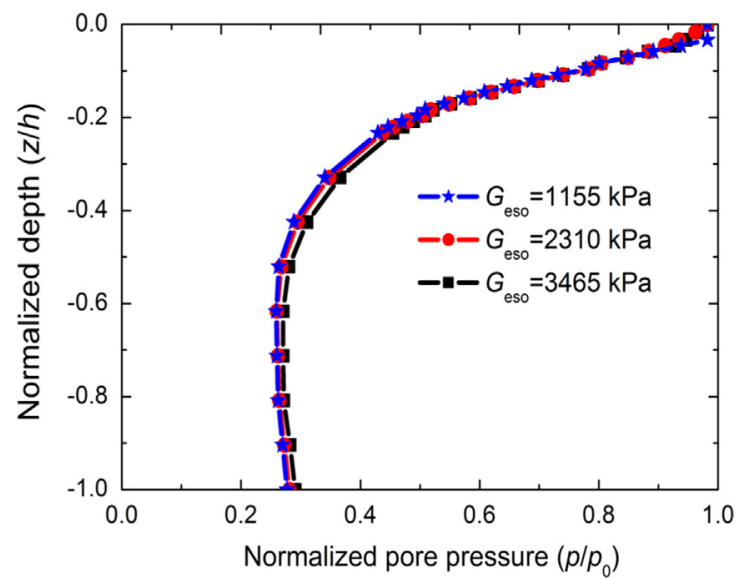

Fig. 13. Vertical distribution of normalized pore pressure $p / p_{0}$ versus $z / h$ with variable soil shear modulus.

leads to the change of $G_{e s o}$. For convenience of description, $G_{e s o}$ is examined in this analysis. Fig. 13 shows the vertical distributions of normalized pore pressure versus soil depth of various $G_{e s o}$ $\left(G_{\text {eso }}=1155 \mathrm{kPa}, 2310 \mathrm{kPa}\right.$ and $\left.3465 \mathrm{kPa}\right)$. As shown in Fig. 13, it can be observed that there is no big difference among different shear modulus of soil. They show the same trend with increase in the soil depth. The pore pressure decreases firstly as soil depth increases up to a certain depth, and then changes slightly until to the lower part of seabed.

\subsection{Effects of wave period to the distribution of pore pressure along seabed depth}

Wave period is an important variable in the determination of wavelength that has been involved in most wave characteristics. Fig. 14 illustrates the vertical distributions of normalized pore pressure versus soil depth for various values of wave period $(T=5.0 \mathrm{~s}, 7.5 \mathrm{~s}$ and $10.0 \mathrm{~s})$. Fig. 14 clearly demonstrates the significant influence of different wave periods on normalized pore pressure with elasto-plastic soil behavior. The pore pressure with different wave periods decreases as soil depth increases up to a certain depth (about $z / h=0.5$ ), and then changes slightly as soil depth increases. Furthermore, it is noted that as the wave periods increase, the normalized pore pressures have slight difference at the above part of seabed, but it increases normally in order at the under part of seabed as the wave periods increase. 


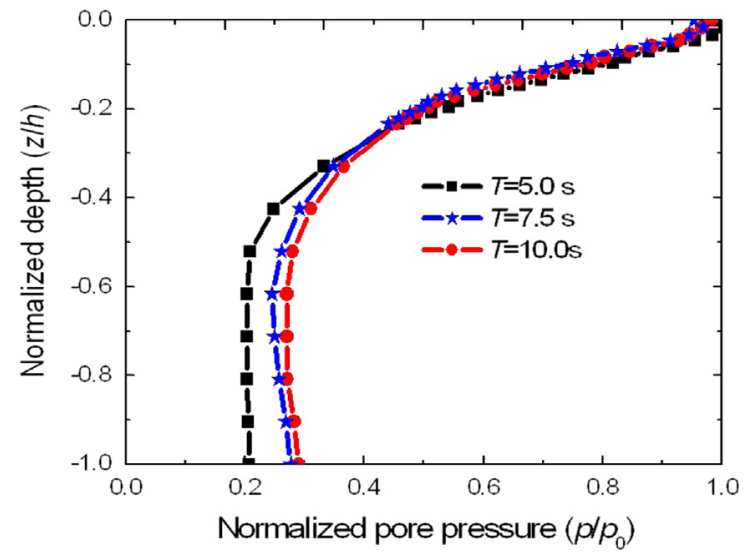

Fig. 14. Vertical distribution of normalized pore pressure $p / p_{0}$ versus $z / h$ with variable wave period.

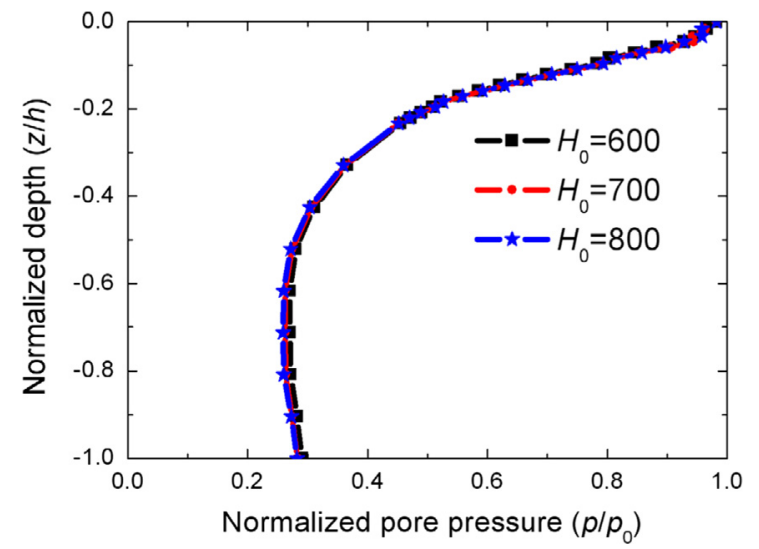

Fig. 15. Vertical distribution of normalized pore pressure $p / p_{0}$ versus $z / h$ with variable soil elasto-plastic parameter.

\subsection{Effects of soil elasto-plastic parameter to the distribution of pore pressure along seabed depth}

Soil stress-strain property is another characteristic that may affect the wave-induced pore pressure inside the seabed. As shown in Eq. (9), the volumetric strain change of soil affects the storage capacity in the pores, and then subsequently influences the pore pressure via the equation of mass conservation for the fluid phase. For the elasto-plastic model, the strain change can be divided into elastic and plastic part. As for the change of plastic strain, $H_{0}$ is one of the most important parameters.

Fig. 15 plots the distribution of normalized pore pressure versus soil depth for various values of $H_{0}=600,700$ and 800 . As shown in the figure, the value of pore pressure at the fluid node plotted in the figure with various value of $H_{0}$ is almost the same; the difference among them can be neglected.

\section{Conclusions}

In this study, the three-dimensional poro-elasto-plastic Finite Element Method model with submarine pipelines was proposed. In this model, the Pastor Zeinkiewicz mark III elasto-plastic model is employed to describe soil plastic behavior of marine sediments under wave loading. Based on the numerical results presented above, the following conclusions can be drawn:

(1) The 3D poro-elasto-plastic model proposed in describing the elasto-plastic properties of soil has noticeable difference with elastic model. The poro-elasto-plastic behaviors of soil have more significant influence on wave-induced pore pressure of seabed around submarine pipeline.

(2) With any variable soil characteristics, wave characteristics and elasto-plastic parameters examined in this analysis, the distribution of normalized pore pressures has the same trend: decreases rapidly at the upper part of seabed, and then changes slightly at the lower part of the seabed as the seabed depth increases.

(3) The effect of permeability coefficient of soil on normalized pore pressure of seabed is remarkable. Small reduction of permeability coefficient leads to remarkable change of normalized pore pressure of seabed. Therefore, the pipelines may be protected using coarse material of high permeability to cover layers to dissipate the pore pressure.

\section{Acknowledgments}

The authors wish to express their gratitude to the supports from China National Natural Science Foundation for Young Scientists through the Grant 51308014, the supports from Specialized Research Fund for the Doctoral Program of Higher Education of China through the Grant 20121103120027 and Beijing City Board of Education Scientific Research Project on the project through the Grant km201410005021 are mostly grateful. The research is also supported by China Postdoctoral Science Foundation funded project (Project no. 2014M550581) and Beijing city Postdoctoral Science Foundation funded project (Project no. 201422-50).

\section{References}

[1] Bijker EW, Leeuwenstein N. Interaction between pipelines and the seabed under the influence of waves and currents. Seabed Mech. London: Graham and Trotman; 1984:235-42.

[2] Biot MA. General theory of three-dimensional consolidation. J Appl Phys 1941:12:155-64.

[3] Biot MA. Theory of propagation of elastic waves in a fluid-saturated porous solid, part $\|-$ low-frequency range, part $\|-$ higher-frequency range. J Acoust Soc Am 1956;28(2):168-78.

[4] Cheng AHD, Liu PLF. Seepage force on a pipeline buried in a poroelastic seabed under wave loading. Appl Ocean Res 1986;8(1):22-32.

[5] Gökce T, Sumer BM and Fredsøe J. Scour around the head of a vertical-wall breakwater. In: Proceedings of the international conference on hydrotechnical engineering for port and harbor construction. Yokosuka, Japan; 1994. p. 1097-116.

[6] Hsu JRC, Jeng DS. Wave-induced soil response in an unsaturated anisotropic sea of finite thickness. Int J Numer Anal Methods Geomech 1994:18 (11):785-807

[7] Jeng DS. Soil response in cross-anisotropic seabed due to standing waves. J Geotech Geoenviron Eng 1997;123(1):9-19.

[8] Jeng DS. Wave-induced seabed response in front of a breakwater. (Ph.D. thesis). The University of Western Australia; 1997.

[9] Jeng DS, Cha DH. Effects of dynamic soil behaviour and wave nonlinearity on the wave-induced pore pressure and effective stresses in porous seabed Ocean Eng 2003;30(16):2065-89.

[10] Luan MT, Qu P, Jeng DS, Guo Y, Yang Q. Dynamic response of a porous seabedpipeline interaction under wave loading: soil-pipeline contact effects and inertial effects. Comput Geotech 2008;35:173-86.

[11] Madsen OS. Wave-induced pore pressure and effective stresses in a porous bed. Geotechnique 1978;28:377-93.

[12] Magda W. Wave-induced uplift force acting on a submarine buried pipeline: finite element formulation and verification of computations. Comput Geotech 1996;19(1):47-53.

[13] Magda W. Wave-induced uplift force on a submarine pipeline buried in a compressible seabed. Ocean Eng. 1997;24(6):551-76.

[14] Mei CC, Foda MA. Wave-induced stresses around a pipe laid on a pore-elastic sea bed. Geotechnique 1981;31:509-17.

[15] Nago H, Maeno S, Matsumoto T et al. Liquefaction and densification of loosely deposited sand bed under water pressure variation. In: Proc 3rd Int Offshore Polar Eng Conf Singapore; 1993. p. 578-84.

[16] Ou JH. Three-dimensional numerical modeling of interaction between soil and pore fluid. (Ph.D. thesis). University of Birmingham; 2009. 
[17] Pastor M and Zienkiewicz OC. A generalised plasticity, hierarchical model for sand under monotonic and cycle loading. In: Ghent GN, Pande WF, Van IMPE. Proceedings of the NUMOG II conference; 1986.

[18] Sumer BM, FredsØe J, Christensen S, et al. Sinking/floating of pipelines and other objectives in liquefied soil under waves. Coast Eng 1999;38(2):53-90.

[19] Teh TC. Stability of marine pipelines on unstable and liquefied seabed. (Ph.D. thesis). University of Cambridge; 2003.

[20] Turcotte BR, Liu PLF, Kulhawy FH. (Joseph H. DeFree Hydraulic Laboratory Report 84-1). Laboratory evaluation of wave tank parameters for wavesediment interaction. School of Civil and Environmental Engineering, Cornell University; 1984.
[21] Pan DZ, Wang LZ, Pan CH, et al. Experimental investigation on the waveinduced pore pressure around shallowly embedded pipelines. Acta Oceanol Sin 2007;26(5):125-35.

[22] Yamamoto T, Koning HL, Sellmeiher H, et al. On the response of a poro-elastic bed to water waves. J Fluid Mech 1978;87:193-206.

[23] Zen K, Yamazaki H. Mechanism of wave-induced liquefaction and densification in seabed. Soils Found 1990;30(4):90-104.

[24] Zhang XL, Jeng DS, Luan MT. Dynamic response of a porous seabed around pipeline under three-dimensional wave loading. Soil Dyn Earthq Eng 2011;31 (5-6):785-91.

[25] Zienkiewicz OC, Chan AHC, Pastor M, et al. Computational geomechanics with special reference to earthquake engineering. Chichester, UK: Wiley; 1999. 